\title{
AVALIAÇÃO DE CULTIVARES DE MANGUEIRA SELECIONADAS PELO INSTITUTO AGRONÔMICO DE CAMPINAS COMPARADAS A OUTRAS DE IMPORTÂNCIA COMERCIAL ${ }^{1}$
}

\author{
CÁSSIA REGINA LIMONTA CARVALHO², CARLOS JORGE ROSSETTOO,6, DILZA MARIA BASSI MANTOVANI ${ }^{4}$, \\ MARCELO ANTÔNIO MORGANO5, JOSALBA VIDIGAL DE CASTRO², NELSON BORTOLETTO ${ }^{3}$
}

\begin{abstract}
RESUMO - Duas novas cultivares com resistência à seca-da-mangueira obtidas pelo Instituto Agronômico de Campinas, IAC 103 Espada Vermelha e IAC 109 Votupa, foram avaliadas em comparação com quatro cultivares de origem americana cultivadas no Estado de São Paulo: Tommy Atkins, Van Dyke, Palmer e IAC Haden 2H. Esta última é um clone selecionado da 'Haden 2H’. Foram avaliadas a produção, resistência às doenças e mosca-dasfrutas bem como as características físicas e químicas dos frutos. A produtividade das cultivares foi avaliada em Votuporanga-SP, utilizando um ensaio em blocos completos ao acaso, com as seis cultivares e cinco repetições, com três plantas por parcela. A cultivar Palmer mostrou-se a mais produtiva, revelando boa adaptação às condições edafoclimáticas do local. Nenhuma cultivar foi resistente a todas as doenças, e a 'Haden $2 \mathrm{H}$ ' foi a mais suscetível. A 'Espada Vermelha' mostrou-se resistente à mosca-das-frutas, e a 'Votupa' apresentou a maior porcentagem de polpa, próxima à das comerciais ‘Van Dyke', ‘Tommy Atkins' e 'Palmer'. O valor nutritivo e a composição química dos frutos foram avaliados no Instituto Agronômico e no Instituto de Tecnologia de Alimentos, em Campinas. A cultivar Espada Vermelha distinguiu-se das demais por ter apresentado características diferenciadas em alguns dos parâmetros químicos avaliados, principalmente quanto aos teores de minerais, carotenóides totais e de lipídeos, que proporcionaram intenso aroma e coloração aos seus frutos. 'Votupa', 'Palmer' e 'Van Dyke’ apresentaram frutos mais ácidos e mais calóricos, enquanto as cultivares Espada Vermelha, Tommy Atykns e Haden 2H mostraram frutos de baixa acidez e de menor valor calórico.
\end{abstract}

Termos para indexação: Mangifera indica, produtividade, doenças, mosca-das-frutas, características físicas, composição química.

\section{EVALUATION OF MANGO CULTIVARS SELECTED BY “INSTITUTO AGRONÔMICO DE CAMPINAS” COMPAIRED TO OTHERS OF COMMERCIAL IMPORTANCE}

\begin{abstract}
Two new mango cultivars, IAC 103 Espada Vermelha and IAC 109 Votupa, resistant to the mango wilt caused by the fungus Ceratocystis fimbriata and selected by the "Instituto Agronômico de Campinas" (IAC), were compaired to four Floridian cultivars used for commercial production in the State of São Paulo: Tommy Atkins, Van Dyke, Palmer and IAC Haden 2H. This last one is a clone selected from the Haden 2H cultivar. The yield capacity of the cultivars was evaluated in a field experiment with six cultivars, five replications and three plants per plot, using a completely randomized blocks design, in Votuporanga, State of São Paulo. The yield, resistance to diseases and fruit-fly as well as physical and chemical parameters of the fruits were evaluated. The cultivar Palmer was the most productive, with good adaptation to the local soil and climatic conditions. 'Haden 2H' was the most susceptible cultivar. There was no cultivar resistant to all diseases and 'Espada Vermelha' showed some resistance to fruitfly. The proportion of peel, pulp and seeds of the fruits were evaluated. The cultivar Votupa showed the highest percentage of pulp, which was similar to the commercial cultivars Van Dyke, Tommy Atkins and Palmer. To evaluate the nutritive value of the cultivars, the chemical composition of the fruits were made in "Instituto Agronômico de Campinas" and "Instituto de Tecnologia de Alimentos", both located in Campinas, State of São Paulo. The fruits were analysed for $\mathrm{pH}$, soluble solids ( ${ }^{\circ}$ Brix), total acidity, lipids, total protein, residual fixed minerals (ash), pectin, ascorbic acid, total carotene, total alimentary fibers, total carbohidrates and calories, and the content of calcium, cupper, iron, phosphorus, magnesium, manganese, potassium and zinc. The cultivar "Espada Vermelha" differed from the others by the chemical parameters, mainly in the mineral composition and in the content of total carotenoids and lipids, which provided intense flavor and coloration to its fruits. 'Votupa', 'Palmer' and 'Van Dyke' presented higher acidity and caloric fruits, whereas ‘Espada Vermelha', ‘Tommy Atykns’ and 'Haden 2H’ had fruits less caloric and with lower acidity.
\end{abstract}

Index terms: Mangifera indica, productivity, diseases, fruit-fly, physical traits, chemical composition.

\section{INTRODUÇÃO}

A manga (Mangifera indica L.), uma das mais populares frutas tropicais, originária do sudeste asiático, foi introduzida no Brasil no século XVI, dando origem, através de sementes, a diversas variedades cultivadas, as quais representavam até a década de 60 a mangicultura brasileira (Subramanyam et al., 1975; Botrel, 1994; Donadio, 1996).

A exportação da fruta teve crescimento significativo, passando de 625 toneladas em 1981 a 94.291 toneladas em 2001, sendo a América do Norte e a Comunidade Européia os principais importadores (Souza et al., 2002).

Esse acréscimo da exportação deu-se com a introdução, nos Estados de São Paulo e de Minas Gerais, em meados da década de 70, de novas cultivares vindas da Flórida (EUA), as quais ganharam notoriedade, importância social e econômica e, conseqüentemente, boa aceitação pelos fruticultores. Paralelamente à atividade de exportação da fruta, ocorreu em nosso País uma forte migração da população do campo para as cidades, promovendo aumento de demanda de produtos até então consumidos na zona rural. Todos estes fatores contribuíram para o fortalecimento da mangicultura brasileira com expansão da área cultivada.

Grande parte da produção da manga ainda é consumida na forma in natura, sendo o Nordeste e Sudeste as principais regiões produtoras, com $84 \%$ da produção nacional concentrada nos Estados de São Paulo (23\%), Bahia (22\%), Pernambuco (11\%), Minas Gerais (10\%), Ceará (7\%), Paraíba (7\%) e Piauí (4\%) (Souza et al., 2002).

Hoje em dia, devido às diferentes cultivares, à diversidade das regiões produtoras, aos plantios tecnificados e à aplicação da indução floral, encontramos com certa facilidade mangas em feiras livres, supermercados e varejões durante todo o ano, atingindo as frutas no

\footnotetext{
(Trabalho 097/2003). Recebido: 20/07/2003. Aceito para publicação: 23/04/2004.

${ }^{2}$ Pesquisadoras Científicas, Instituto Agronômico de Campinas - IAC/APTA/SAA - Caixa Postal 28, 13001-970 Campinas-SP. Fone: (19) 3241-5188, climonta@iac.sp.gov.br; josalba@iac.sp.gov.br.

${ }^{3}$ Pesquisadores Científicos, Pólo Regional de Desenvolvimento Tecnológico dos Agronegócios do Noroeste Paulista - APTA/SAA - Caixa Postal 61, 15500-000, Votuporanga-SP. Fone: (17) 3421-8148, rossetto@iac.sp.gov.br; polonoroestepaulista@apta.sp.gov.br.

${ }^{4}$ Pesquisadora Científica, Instituto de Tecnologia de Alimentos - ITAL/APTA/SAA, Caixa Postal 139, 13012-970, Campinas-SP. Fone: (19) 3743-1776, dilza@ital.org.br. ${ }^{5}$ Químico, Instituto de Tecnologia de Alimentos - ITAL/APTA/SAA, SP. Fone: (19) 3743-1778, morgano@ital.org.br.

${ }^{6}$ Bolsista do CNPq.
} 
período de março a setembro, melhor preço para o fruticultor. A safra no Estado de São Paulo ocorre de novembro a março com pico entre dezembro e primeira quinzena de janeiro. Em Minas Gerais, a produção de manga dá-se no mesmo período de São Paulo, enquanto nos Estados do Nordeste pode estender-se, devido às boas condições edafoclimáticas da região, de agosto a novembro (Couto et al., 1996; São José, 1996).

Das cultivares de importância comercial, a Tommy Atkins é a mais cultivada e exportada no País por ter boa produtividade, boa capacidade de adaptação a diferentes ambientes de cultivo, maior tolerância a certas doenças, como o oídio, a antracnose e a verrugose, além de apresentar frutos com qualidade razoável e boa conservação pós-colheita. Em seguida, vêm as cultivares Haden, Keitt, Palmer e Van Dyke. A ‘Tommy Atkins', 'Haden’ e ‘Keitt’ constituem cerca de 92\% da área plantada no Vale do Rio São Francisco (Brasil, 1999).

Vale salientar que os mercados consumidores (interno e externo) de mangas ainda estão em expansão, visto que, em termos nutricionais, há a tendência mundial de consumir frutas tropicais frescas em detrimento das industrializadas.

Buscando auxiliar e fortalecer a mangicultura brasileira, o Instituto Agronômico de Campinas (IAC), tradicionalmente, vem estudando tanto o comportamento agronômico como as características físicas e químicas de novas cultivares, quanto à produtividade, resistência a doenças e pragas, descrição física e qualitativa da manga.

Dessa forma, um experimento com mangueiras instalado no Pólo Regional de Desenvolvimento Tecnológico dos Agronegócios do Noroeste Paulista, da Agência Paulista de Tecnologia dos Agronegócios, Votuporanga-SP, foi avaliado sob as perspectivas agronômica e nutricional, com o objetivo de avaliar novas cultivares selecionadas pelo IAC, comparando-as com algumas cultivares tradicionalmente comercializadas nos mercados interno e externo.

\section{MATERIAL E MÉTODOS}

Um experimento envolvendo cultivares de manga recentemente selecionadas pelo Instituto Agronômico de Campinas (IAC 103 Espada Vermelha e IAC 109 Votupa), de um clone comercial (IAC Haden 2H) e de outras três cultivares tradicionais (Palmer, Tommy Atkins e Van Dyke), foi instalado usando delineamento de blocos completos ao acaso, com seis tratamentos (cultivares) e cinco repetições, sendo as parcelas compostas de três plantas úteis. As plantas foram estabelecidas no espaçamento de $9 \mathrm{~m}$ entre linhas e $8 \mathrm{~m}$ entre plantas nas linhas, perfazendo 139 árvores por hectare. O plantio das mudas no campo experimental foi feito em $1^{\circ}$-081995, usando como porta-enxerto a cultivar Manila, denominada anteriormente pelo IAC como Carabao. Os tratos culturais realizados seguiram as técnicas normalmente recomendadas para a cultura na região.

As cultivares empregadas no estudo apresentam as seguintes origens: IAC 103 Espada Vermelha (EV), selecionada em Mococa-SP e lançada em 08-01-1998, sendo segregante e descendente da cultivar Manila com pai desconhecido; IAC 109 Votupa (V), descendente de mãe Tommy Atkins e pai desconhecido; IAC Haden 2H (H), clone selecionado dentro da cultivar americana Haden $2 \mathrm{H}$ e as cultivares Palmer (P), Tommy Atkins (TA) e Van Dyke (VD) originadas da Flórida, USA, introduzidas e cultivadas no Brasil.

As doenças antracnose, oídio e malformação da inflorescência foram avaliadas no campo experimental de Votuporanga, atribuindo-se a escala de nota visual: 0 - totalmente resistente; 1 - moderadamente resistente; 2 - moderadamente suscetível; 3 - suscetível, e 4 - totalmente suscetível. O comportamento varietal em relação à seca-da-mangueira, expresso nessa escala de 0 a 4, é uma adaptação de resultados anteriormente publicados (Rossetto et al., 1996), visto que, na área experimental de Votuporanga, não ocorreu essa doença.

Na safra de 1999-2000, frutos maduros foram colhidos de acordo com a época de maturação de cada variedade e avaliados quanto às medidas físicas e à composição química. Para estabelecer as medidas físicas, foram utilizados 20 frutos de cada cultivar, determinando-se o comprimento, largura, espessura, pesos total, do caroço, da casca e da polpa, e as porcentagens de casca, caroço e polpa para cada uma das cultivares. Para compor a amostragem química da cultivar, usaram-se 10 frutos por cultivar. As polpas dos frutos foram homogeneizadas por meio de um triturador doméstico para determinação de $\mathrm{pH}$, sólidos totais, sólidos solúveis totais expressos em ${ }^{\circ}$ Brix, acidez total (titulável) expressa em porcentagem de ácido cítrico, a relação sólidos solúveis totais/acidez (SST/acidez), lipídeos, proteína bruta, resíduo mineral fixo (cinzas), pectina, ácido ascórbico, carotenóides totais, fibra alimentar total (FAT), carboidratos totais, calorias e dos minerais cálcio, cobre, ferro, fósforo, magnésio, manganês, potássio e zinco. As medidas químicas foram realizadas com três repetições analíticas para cada amostra, empregandose métodos analíticos descritos por Carvalho et al. (1990), Cunnif (1998) e por IMO Industries Inc. (1990).

Para o cálculo do intervalo de confiança das médias de todas as determinações físicas e químicas realizadas, foi utilizada a fórmula (s.t/ $\left.\mathrm{r}^{1 / 2}\right)$, em que s é desvio-padrão da média, t é o valor tabelado ao nível de $5 \%$ e r é o número de repetições analíticas.

Com a finalidade de melhor interpretar os resultados das medidas físicas e químicas, empregou-se a técnica de Análise de Componentes Principais (ACP) descritas por Sharaf et al. (1986), Beebe et al. (1998) e por Morgano et al. (1999), fazendo uso do software Pirouette 3.02 (Infometrix, Seatlle, WA, 2001). Para que as variáveis (constituintes determinados) passassem a ter a mesma magnitude de valores, os dados gerados foram auto-escalados antes de se aplicar o método de ACP. O auto-escalamento consistiu na determinação da média geral para cada variável, a qual foi subtraída de cada valor unitário referente a cada amostra, e os valores encontrados foram divididos pelo desvio-padrão da média.

A ACP baseia-se na combinação linear das variáveis avaliadas, agrupando aquelas altamente correlacionadas em uma nova variável denominada componente principal (CP). Assim, a matriz (X) constituída pelas medidas físicas ou pelas medidas químicas foi decomposta $(\mathrm{X}=\mathrm{T}$ $\mathrm{L}^{\mathrm{T}}$ ) em duas novas matrizes: a de escores $(\mathrm{T})$ e a de pesos $\left(\mathrm{L}^{\mathrm{T}}\right)$, representadas pelos gráficos de escores e de pesos. Deste modo, o gráfico de escores consiste na distribuição gráfica das amostras avaliadas, em espaço bidimensional, após aplicação da ACP, e o gráfico de pesos descreve a influência das variáveis (no caso, das medidas físicas ou químicas) na distribuição gráfica das amostras, ou seja, do gráfico de escores.

A produção das cultivares foi avaliada em duas safras consecutivas, aos seis anos de idade (safra 2001-2002) e sete anos de idade (safra 2002-2003). Os frutos presentes nas árvores foram contados, e o peso médio dos frutos de cada cultivar foi obtido pela pesagem de 10 frutos. O número de frutos multiplicado pelo peso médio deu o peso de frutos produzido por árvore, e este foi transformado em peso por hectare. As médias das parcelas de três plantas, expressas em peso por hectare, serviram para a comparação da produtividade das cultivares, empregandose o teste de Tukey, a 5\% de probabilidade, para discriminar as médias.

$\mathrm{O}$ grau de ataque da mosca-das-frutas foi avaliado em duas safras consecutivas, 2001-2002 e 2002-2003, em condições de infestação natural de campo em Votuporanga. Foram avaliados 30 frutos de cada cultivar, na fase de maturação, cortando-se longitudinalmente o fruto, em ambos os lados do caroço e estimando-se visualmente, em cada lado, a porcentagem da polpa do fruto infestada pela mosca-das-frutas. Foi obtida uma média para cada fruto, somando-se a porcentagem infestada de cada lado e dividindo-se por dois. Somando-se as médias de cada fruto e dividindo-se por 30, foi calculada uma média geral de intensidade de polpa infestada dos 30 frutos. Esta foi denominada porcentagem média da intensidade de infestação da polpa. Outrossim, frutos com qualquer grau de infestação foram considerados infestados, e aqueles sem nenhum sinal de infestação, em ambos os lados cortados, foram considerados não infestados. Obteve-se, assim, uma porcentagem de frutos infestados e não infestados pela mosca. A classificação da cultivar como resistente ou suscetível à mosca é relativa à infestação das demais cultivares. No presente trabalho, foi adotada a seguinte escala com base na porcentagem dos frutos infestados: até 3,9\% - muito resistente; 4 a 10,9\% - resistente; 11 a 24,9\% - resistência moderada; 25 a 70,9\% suscetível, e 71 a 100\% - muito suscetível. 


\section{RESULTADOS E DISCUSSÃO}

Baseando-se na escala de época de produção/maturação dos frutos, estabelecida pelos autores Donadio et al. (1982) e atualizada por Donadio (1996), pode-se classificar como precoces, nas condições climáticas de Votuporanga (região quente)-SP, as cultivares Espada Vermelha (EV), Haden 2H (H) e Van Dyke (VD), colhidas em novembro; como de meia-estação, a cultivar Tommy Atkins (TA), colhida em dezembro, e como tardias, a Votupa (V) e Palmer (P), colhidas de dezembro a janeiro.

As produtividades, em $\mathrm{kg} / \mathrm{ha}$, das seis cultivares com seis e sete anos de idade das plantas, são demonstradas na Tabela 1. Dentre as cultivares plantadas, a ‘Espada Vermelha' foi a menos produtiva devido ao menor porte de suas árvores e ao pequeno tamanho dos frutos. Ela deve ser plantada em espaçamento mais adensado. Outrossim, esta cultivar oferece perspectiva favorável para ser cultivada no Estado de São Paulo, por ser mais precoce que a 'Tommy Atkins' e ser responsiva à indução floral com PBZ (paclobutrazol), com produção na entressafra, em setembro (Rossetto et al., 2002). A ‘Votupa’ obteve produção intermediária comparável à 'Van Dyke' e 'Tommy Atkins'. Nota-se, na Tabela 1, que, em geral, as cultivares produziram mais na safra 2002-2003 do que em 2001-2002, provavelmente devido à diferença de idade das plantas. A 'Haden' foi a cultivar mais produtiva em 2001-2002, mas sua produtividade, ao contrário das demais cultivares, caiu em 2002-2003, provavelmente devido à forte onda de calor que ocorreu em 2002-2003, provocando intensa queda de seus frutos. Pinto et al. (2002) relataram que a 'Haden' apresenta elevada alternância de produção, o que ocorreu em Votuporanga, e também tem alto índice de aborto dos frutos nas condições do semi-árido. Esta cultivar, aparentemente, é mais sensível ao calor do que as demais. A cultivar Palmer, na média dos dois anos, foi a mais produtiva, demonstrando ser uma cultivar que se adaptou muito bem às condições de fertilidade e clima do Estado de São Paulo.

Algumas doenças não só reduzem a quantidade dos frutos produzidos, como comprometem a qualidade dos frutos. A Tabela 2 mostra o comportamento das cultivares em relação às principais moléstias que atacam a cultura. Nota-se que a cultivar Haden foi a mais suscetível às doenças. De fato, isso contribuiu para reduzir a área cultivada com a 'Haden' no Estado de São Paulo. Muitos pomares da 'Haden' foram dizimados pela seca-da-mangueira (Piza Jr. e Ribeiro, 1996), e pomares dessa cultivar

TABELA 1 - Produção, em kg/ha, de seis cultivares de mangueira com seis (2001-2002) e sete (2002-2003) anos de idade, obtidas em ensaio de blocos completos ao acaso. Pólo Regional de Desenvolvimento Tecnológico dos Agronegócios do Noroeste Paulista, Votuporanga-SP

\begin{tabular}{lcc}
\hline Cultivares & $\mathbf{2 0 0 1 - 2 0 0 2}$ & $\mathbf{2 0 0 2 - 2 0 0 3}$ \\
\hline Haden 2H & $21.222 \mathrm{a}^{*}$ & $16.040 \mathrm{~b}^{*}$ \\
Palmer & $18.469 \mathrm{ab}$ & $26.231 \mathrm{a}$ \\
Votupa & $15.119 \mathrm{bc}$ & $19.692 \mathrm{ab}$ \\
Van Dyke & $14.169 \mathrm{bc}$ & $18.867 \mathrm{ab}$ \\
Tommy Atkins & $11.400 \mathrm{c}$ & $14.036 \mathrm{~b}$ \\
Espada Vermelha & $10.105 \mathrm{c}$ & $13.233 \mathrm{~b}$ \\
\hline Coeficiente de Variação (\%) & 19,7 & 28,7
\end{tabular}

* Médias seguidas pela mesma letra nas colunas não diferem entre si, pelo teste de Tukey, a 5\%. avaliados em seis municípios do Estado de São Paulo apresentaram 57,2\% de inflorescências malformadas (Rossetto et al., 1989). A ‘Haden’ e a ‘Espada Vermelha' foram suscetíveis à antracnose. Todas as cultivares avaliadas foram suscetíveis à malformação da inflorescência, uma doença que reduz a produtividade da mangueira. Nenhuma cultivar estudada apresentou resistência a todas as principais doenças da mangueira.

TABELA 2 - Comportamento das cultivares em relação às doenças da mangueira. Pólo Regional de Desenvolvimento Tecnológico dos Agronegócios do Noroeste Paulista, Votuporanga-SP.

\begin{tabular}{lcccc}
\hline Cultivares & Oídio & Antracnose & $\begin{array}{c}\text { Malformação } \\
\text { inflorescência }\end{array}$ & $\begin{array}{c}\text { Seca-da- } \\
\text { mangueira }\end{array}$ \\
\hline Espada & 1 & 3 & 3 & 1
\end{tabular}

\begin{tabular}{lllll} 
Vermelha & & 3 & 3 & \\
Haden 2H & 2 & 3 & 3 & 4 \\
Votupa & 3 & 2 & 3 & 1 \\
Palmer & 1 & 2 & 3 & 3 \\
Tommy Atkins & 1 & 1 & 3 & 3 \\
Van Dyke & 1 & 1 & 3 & 2 \\
\hline
\end{tabular}

0 - totalmente resistente; 1 - moderadamente resistente; 2 - moderadamente suscetível; 3 - suscetível; 4 - totalmente suscetível.

A Tabela 3 demonstra as porcentagens de frutos infestados e a intensidade de polpa infestada pela mosca-das-frutas obtidas nas safras de 2001-2002 e 2002-2003. A infestação natural de mosca-das-frutas no local da experimentação (Votuporanga-SP) foi muito alta nos dois anos agrícolas observados. A ‘Espada Vermelha’ destacou-se pelo baixo grau de infestação de mosca-das-frutas, podendo ser considerada resistente em relação às demais cultivares. Em parte, sua menor infestação é devida à sua precocidade, tendo a maturação dos frutos em época que o nível populacional da mosca é menor. Isso foi conceituado como falsa resistência do tipo evasão hospedeira (Painter, 1951). Outrossim, seus frutos têm pedúnculo longo e ficam muito expostos ao sol, reduzindo a sua procura pela mosca, que prefere locais sombreados. Além desses dois componentes, devem existir outros fatores na casca da fruta que lhe conferem a resistência.

Avaliando as características físicas dos frutos demonstradas na Tabela 4 e por meio de comparação simultânea dos gráficos (Figuras 1a e 1b) obtidos utilizando a técnica de ACP, percebe-se que a cultivar Votupa destaca-se à direita do gráfico de escores por apresentar frutos com os maiores valores médios de largura $(9,7 \mathrm{~cm})$, espessura $(8,3 \mathrm{~cm})$, peso total (596,3 g) e peso da polpa (512,8 g) (variáveis posicionadas à direita do gráfico de pesos). Embora tenha os maiores valores médios de peso de casca (49,3 g), apresentou a menor porcentagem de caroço (5,7\%), rendendo, dessa forma, a maior porcentagem de polpa $(86,0 \%)$, propriedades estas de grande importância para o processamento industrial. Aplicando a classificação estabelecida por Donadio et al. (1982) para mangas em relação ao peso médio dos frutos: frutos pequenos (< 250 g); médios (250 a 350 g); grandes (350 a 500 g); muito grandes (> $500 \mathrm{~g})$, os frutos da cultivar Votupa são considerados como muito grandes (>500g).

Inversamente à cultivar Votupa, os frutos da cultivar Espada Vermelha obtiveram os menores valores de largura $(6,5 \mathrm{~cm})$ e de espessura

TABELA 3 - Porcentagem de frutos infestados pela mosca-das frutas, intensidade de polpa infestada expressa em porcentagem e conceito de grau de resistência varietal. Pólo Regional de Desenvolvimento Tecnológico dos Agronegócios do Noroeste Paulista , Votuporanga-SP, 20012002 e 2002-2003.

\begin{tabular}{lccccc}
\hline \multirow{2}{*}{ Cultivares } & Porcentagem de frutos infestados & Intensidade de polpa infestada em \% & $\begin{array}{c}\text { Nível de resistência ou } \\
\text { suscetibilidade }\end{array}$ \\
\cline { 2 - 5 } & $\mathbf{2 0 0 1 - 2 0 0 2}$ & $\mathbf{2 0 0 2 - 2 0 0 3}$ & $\mathbf{2 0 0 1 - 2 0 0 2}$ & $\mathbf{2 0 0 2 - 2 0 0 3}$ & Resistente \\
Espada Vermelha & 7,2 & 3,3 & 1,2 & 0,1 & Suscetível \\
Votupa & 36,6 & 26,6 & 5,1 & 3,7 & Suscetível \\
Van Dyke & 46,6 & 46,6 & 5,4 & 10,7 & Suscetível \\
Palmer & 47,3 & 46,2 & 11,1 & 13,4 & Suscetível \\
Tommy Atkins & 53,3 & 45,5 & 11,6 & 15,2 & Suscetível \\
Haden 2H & 63,3 & 46,6 & 20,3 & \\
\hline
\end{tabular}


TABELA 4 - Médias e intervalos de confiança, ao nível de 5\%, das medidas físicas de 20 frutos maduros das cultivares de manga estudadas. Pólo Regional de Desenvolvimento Tecnológico dos Agronegócios do Noroeste Paulista, Votuporanga-SP, 1999-2000.

\begin{tabular}{|c|c|c|c|c|c|c|}
\hline \multirow[b]{2}{*}{ Determinações } & \multicolumn{6}{|c|}{ CULTIVAR } \\
\hline & Espada Vermelha & Haden 2H & Votupa & Palmer & Tommy Atkins & Van Dyke \\
\hline Comprimento $(\mathrm{cm})$ & $11,3 \pm 0,3$ & $9,6^{ \pm} 0,4$ & $10,2 \pm 0,4$ & $11,9 \pm 0,4$ & $10,1 \pm 0,4$ & $9,8^{ \pm} 0,4$ \\
\hline Largura (cm) & $6,5^{ \pm} 0,2$ & $8,3 \pm 0,9$ & $9,7 \pm 0,2$ & $7,7 \pm 0,2$ & $8,0 \pm 0,3$ & $7,8 \pm 0,2$ \\
\hline Espessura (cm) & $5,7 \pm 0,2$ & $7,3 \pm 0,2$ & $8,3^{ \pm} 0,2$ & $7,0 \pm 0,2$ & $7,1 \pm 0,3$ & $6,6^{ \pm} 0,2$ \\
\hline Peso total (g) & $264,8 \pm 17,4$ & $346,8 \pm 34,1$ & $596,3 \pm 45,8$ & $426,3 \pm 38,2$ & $397,5 \pm 30,6$ & $328,8 \pm 21,5$ \\
\hline Peso caroço (g) & $26,5 \pm 2,8$ & $29,0 \pm 2,7$ & $34,3 \pm 4,1$ & $40,0 \pm 2,7$ & $31,8 \pm 2,3$ & $24,3 \pm 1,9$ \\
\hline Peso casca $(\mathrm{g})$ & $29,3 \pm 2,4$ & $49,0 \pm 5,8$ & $49,3 \pm 3,4$ & $36,8 \pm 2,5$ & $31,0 \pm 3,3$ & $23,6 \pm 2,8$ \\
\hline Peso polpa (g) & $208,8 \pm 14,1$ & $268,8 \pm 27,4$ & $512,8 \pm 41,3$ & $350,0 \pm 34,1$ & $334,8 \pm 28,3$ & $280,5 \pm 19,4$ \\
\hline Caroço (\%) & $10,0 \pm 0,9$ & $8,4^{ \pm} 0,5$ & $5,8 \pm 0,6$ & $9,5 \pm 0,4$ & $8,1 \pm 0,7$ & $7,4 \pm 0,4$ \\
\hline Casca $(\%)$ & $11,1 \pm 0,6$ & $14,1 \pm 0,9$ & $8,4 \pm 0,6$ & $8,8 \pm 0,6$ & $7,9 \pm 0,7$ & $7,2 \pm 0,8$ \\
\hline Polpa (\%) & $78,9 \pm 1,2$ & $77,5 \pm 0,9$ & $85,9 \pm 0,7$ & $81,8 \pm 0,8$ & $84,0 \pm 1,1$ & $85,4 \pm 1,0$ \\
\hline
\end{tabular}

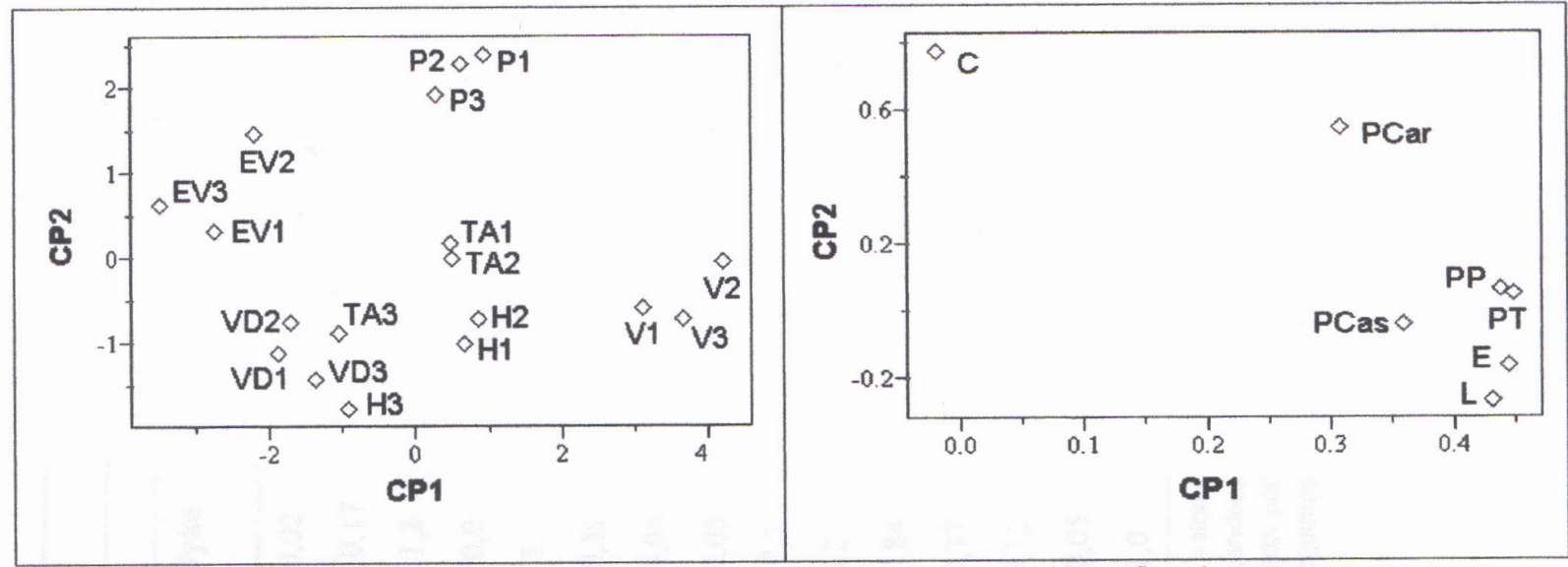

a) gráfico de escores

b) gráfico de pesos

FIGURA 1 - Representações gráficas de componentes principais (CP1 x CP2) obtidas para as medidas físicas dos frutos das diferentes cultivares de manga - pré-processamento utilizado: auto-escalamento. a) gráfico de escores: EV1 a EV3 - Espada Vermelha; VD1 a VD3 - Van Dyke; P1 a P3 - Palmer; TA1 a TA3 - Tommy Atkins; H1 a H3 - Haden 2H; V1 a V3 - Votupa. b) gráfico de pesos: C - comprimento; E espessura; L - largura; PCar - peso do caroço; PCas - peso da casca; PP - peso da polpa; PT - peso total dos frutos.

$(5,7 \mathrm{~cm})$, menores peso total $(264,8 \mathrm{~g})$ e peso da polpa $(208,8 \mathrm{~g})$, demonstrando, portanto, serem de menor tamanho, classificados para este experimento como frutos médios. Esta cultivar apresentou a desvantagem de ter a mais alta porcentagem de caroço $(10,0 \%)$ e a segunda maior porcentagem de casca $(11,1 \%)$, proporcionando menor rendimento da polpa (78,9\%). Entretanto, esta cultivar evidencia-se por ter como atributos de qualidade um forte e agradável aroma e intensa coloração avermelhada da polpa e da casca. As mangas desta cultivar, como as da cultivar Palmer, por serem frutos de formas reniformes, revelaram os maiores comprimentos (com 11,3 e 11,9 cm, respectivamente).

Após a 'Votupa', as mangas 'Palmer' apresentaram os segundos maiores pesos médios totais (426,3 g), considerados frutos grandes, pesos médios de polpa de 350,0 g, com porcentagem de polpa de $81,8 \%$ e elevada porcentagem de caroço (9,5\%).

As cultivares Haden $2 \mathrm{H}$ e Tommy Atkins demonstraram caracteres semelhantes quanto ao peso médio total dos frutos (por volta

TABELA 5 - Composição química das cultivares de manga em estádio maduro. IAC, Campinas-SP, 1999-2000.

\begin{tabular}{|c|c|c|c|c|c|c|}
\hline \multirow[b]{2}{*}{ Determinações $^{1}$} & \multicolumn{6}{|c|}{ CULTIVAR } \\
\hline & Espada Vermelha & Haden 2H & Votupa & Palmer & Tommy Atkins & Van Dyke \\
\hline $\mathrm{pH}$ & $4,52 \pm 0,05$ & $4,18 \pm 0,52$ & $3,85 \pm 0,12$ & $4,16^{ \pm} 0,02$ & $4,37{ }^{ \pm} 0,64$ & $3,81^{ \pm} 0,02$ \\
\hline Sólidos totais (\%) & $17,08 \pm 0,05$ & $17,40 \pm 0,02$ & $20,67 \pm 0,27$ & $20,37 \pm 0,02$ & $16,13 \pm 0,02$ & $21,78 \pm 0,17$ \\
\hline Sólidos solúveis totais $\left({ }^{\circ}\right.$ Brix $)$ & $17,0 \pm 0,7$ & $17,3 \pm 1,0$ & $17,6 \pm 1,7$ & $17,9 \pm 0,5$ & $16,6 \pm 2,2$ & $20,2 \pm 1,2$ \\
\hline Acidez total (titulável) $)^{2}(\%)$ & $0,27 \pm 0,05$ & $0,29 \pm 0,17$ & $0,48 \pm 0,05$ & $0,35^{ \pm} 0,07$ & $0,20 \pm 0,02$ & $0,44 \pm 0,0$ \\
\hline Sólidos solúveis totais/Acidez & $63,1 \pm 9,2$ & $59,1 \pm 4,2$ & $36,3 \pm 6,2$ & $51,7 \pm 9,9$ & $81,8 \pm 4,7$ & $45,6^{ \pm} 1,5$ \\
\hline Lipídeos (\%) & $0,64 \pm 0,15$ & $0,29 \pm 0,07$ & $0,39 \pm 0,05$ & $0,49 \pm 0,15$ & $0,27 \pm 0,10$ & $0,18 \pm 0,10$ \\
\hline Proteína Bruta $^{3}(\%)$ & $0,46 \pm 0,15$ & $0,14 \pm 0,10$ & $0,24 \pm 0,02$ & $0,16 \pm 0,02$ & $0,30 \pm 0,02$ & $0,24 \pm 0,05$ \\
\hline Resíduo mineral fixo (\%) & $0,51 \pm 0,10$ & $0,35 \pm 0,17$ & $0,39 \pm 0,05$ & $0,52 \pm 0,02$ & $0,33 \pm 0,05$ & $0,52 \pm 0,05$ \\
\hline Ácido Ascórbico (mg/100g) & $31,3 \pm 2,7$ & $36,6 \pm 7,2$ & $46,6 \pm 14,4$ & $56,7^{ \pm} 14,4$ & $31,7 \pm 7,2$ & $38,3 \pm 7,2$ \\
\hline Carotenóides totais ${ }^{4}(\mathrm{mg} / 100 \mathrm{~g})$ & $9,4 \pm 0,2$ & $4,5 \pm 0,5$ & $4,4 \pm 1,0$ & $4,0 \pm 0,2$ & $3,4 \pm 0,0$ & $2,1^{ \pm} 0,2$ \\
\hline Açúcares redutores $^{5}(\%)$ & $2,61 \pm 0,42$ & $3,68 \pm 0,30$ & $4,73 \pm 0,69$ & $4,08^{ \pm} 1,12$ & $3,82 \pm 0,05$ & $5,56 \pm 0,84$ \\
\hline Pectina ${ }^{6}(\%)$ & $0,85 \pm 0,05$ & $1,01 \pm 0,05$ & $0,88 \pm 0,30$ & $0,93{ }^{ \pm} 0,10$ & $0,95 \pm 0,20$ & $0,98 \pm 0,37$ \\
\hline Fibra Alimentar Total ${ }^{7} \quad(\%)$ & $1,83 \pm 0,07$ & $2,20 \pm 0,15$ & $1,90 \pm 0,07$ & $1,71^{ \pm} 0,22$ & $1,97 \pm 0,05$ & $2,80 \pm 0,12$ \\
\hline Carboidratos totais $^{8}(\%)$ & $15,16 \pm 0,50$ & $16,28 \pm 0,20$ & $19,11 \pm 0,32$ & $18,78 \pm 0,15$ & $14,99 \pm 0,17$ & $20,35 \pm 0,05$ \\
\hline Calorias $^{9}(\mathrm{kcal} / 100 \mathrm{~g})$ & $68,2 \pm 2,0$ & $68,3 \pm 1,5$ & $80,9 \pm 0,7$ & $80,2 \pm 0,7$ & $63,6 \pm 1,2$ & $84,0 \pm 1,0$ \\
\hline
\end{tabular}

${ }^{1}$ Valores médios de três repetições analíticas com intervalo de confiança da média ao nível de $5 \% ;{ }^{2}$ Expressa em ácido cítrico; ${ }^{3} \% \mathrm{~N} \mathrm{x} 6,25 ;{ }^{4}$ Valores expressos em betacaroteno; ${ }^{5}$ Referem-se aos teores de frutose e glicose; ${ }^{6}$ Expresso como pectato de cálcio; ${ }^{7}$ Refere-se à soma dos polissacarídeos (incluindo as substâncias pécticas) e de lignina que não são digeridos ou absorvidos pelas enzimas humanas no trato gastrointestinal; ${ }^{8}$ Calculado por diferença - neste valor estão incluídos os teores de açúcares redutores, pectina e fibra alimentar total; ${ }^{9}$ Valor calórico calculado utilizando os seguintes coeficientes de conversão: lipídeos - 9kcal/g; proteína bruta e carboidratos $-4 \mathrm{kcal} / \mathrm{g}$. 


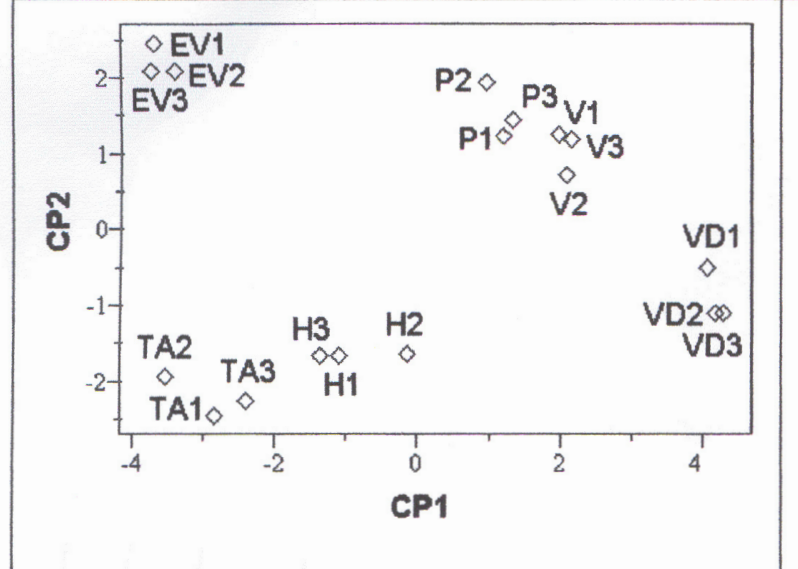

a) gráfico de escores

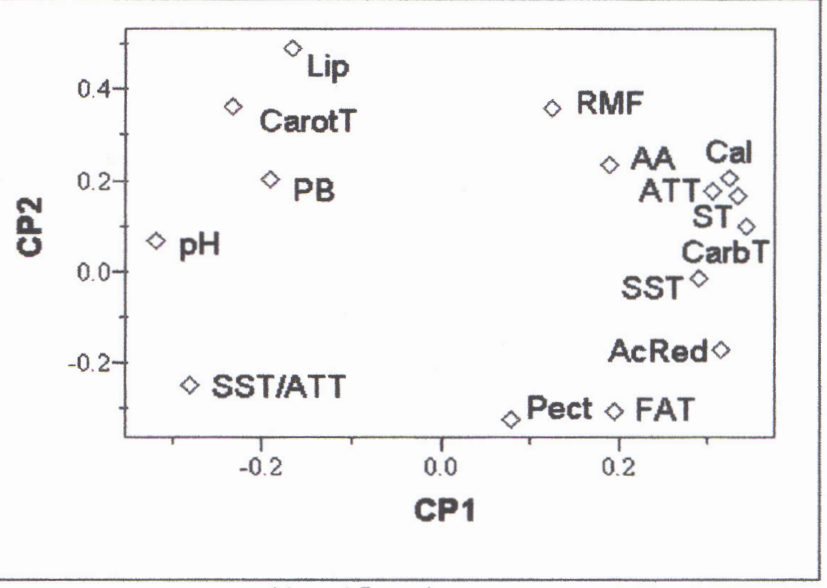

b) gráfico de pesos

FIGURA 2 - Gráficos de componentes principais (CP1 x CP2) obtidos para as características químicas dos frutos - pré-processamento utilizado: autoescalamento. a) gráfico de escores: EV1 a EV3 - 'Espada Vermelha'; TA1 a TA3 - 'Tommy Atkins'; H1 a H3 - 'Haden 2H'; P1 a P3 'Palmer’; V1 a V3 - 'Votupa'; VD1 a VD3 - 'Van Dyke’. b) gráfico de pesos: Lip - lipídeos; CarotT- carotenóides totais; PB - proteína bruta; pH; SST/ATT - relação sólidos solúveis totais/acidez; RMF - resíduo mineral fixo; AA - ácido ascórbico; Cal - calorias; ATT acidez total titulável; ST - sólidos totais; CarbT - carboidratos totais; SST - sólidos solúveis totais ('Brix); AcRed - açúcares redutores; Pect - pectina; FAT - fibra alimentar total.

de $350 \mathrm{~g}$ ) e comprimentos de 9,6 e 10,1 cm, respectivamente (Tabela 4, Figura 1a). Em relação ao peso, os frutos dessas cultivares classificamse como médios a grandes. A 'Haden 2H' apresentou a mais alta porcentagem de casca $(14,1 \%)$, resultando em menor porcentagem de polpa (77,5\%), enquanto as cultivares Tommy Atkins e Van Dyke alcançaram elevados rendimentos de polpa, respectivamente, 84,0 e $85,4 \%$, por terem as menores porcentagens de caroço e de casca.

A preferência do consumidor brasileiro não é regulada pelo tamanho do fruto, mas, sim, pelo seu sabor (Botrel, 1994). Portanto, considerando apenas o peso dos frutos, todas as cultivares selecionadas pelo IAC serão aceitas no mercado interno. Tendo como exigência de mercado externo, frutos com pesos entre 250 a 450 g para o Estados Unidos (Botrel,1994), e até 656 g para a Europa (Genú e Pinto, 2002), as cultivares selecionadas pelo IAC poderão atender a este mercado. Todavia, a suscetibilidade à antracnose encurta a vida de prateleira da 'Espada Vermelha', e a falta de coloração da casca da 'Votupa' são fatores limitantes para exportação. A 'Haden 2H' e as cultivares comerciais (Palmer, Tommy Atkins e Van Dyke) apresentaram os pesos de seus frutos dentro das faixas internacionais de classificação descritas acima.

O conhecimento da composição química da manga é um importante fator para a seleção de cultivares para consumo in natura e visando ao seu processamento. A manga é fonte de carboidratos (fração composta de frutose, glicose, sacarose, amido, fibras e substâncias pécticas), de ácido ascórbico, sais minerais, de ácidos orgânicos com predominância dos ácidos cítrico e málico, e rica fonte de pigmentos carotenóides, tendo alguns atividade provitamínica A, sendo que proteínas e lipídeos estão presentes em menores quantidades (Mukherjee ,1997).

Observando, simultaneamente, a Tabela 5, que traz a composição química das cultivares de manga, com uma das representações gráficas (Figura 2a) da análise multivariada, verifica-se que as cultivares Votupa e Palmer bem como a Haden 2H e Tommy Atkins estão pareadas, por possuírem características químicas similares. A cultivar Van Dyke tem características aproximadas das cultivares Votupa e Palmer, enquanto a 'Espada Vermelha' é distinta.

Comparando o gráfico de pesos (Figura 2b), que descreve a influência das variáveis (determinações químicas) no agrupamento das cultivares com o gráfico de escores (Figura 2a), nota-se que a 'Espada Vermelha' destaca-se graficamente por ter como características químicas os mais elevados teores de carotenóides totais (9,4 mg/100g), lipídeos $(0,64 \%)$, proteína bruta $(0,46 \%), \mathrm{pH}(4,52)$ e o segundo maior valor da relação SST/acidez $(63,1)$. Estes componentes proporcionaram intenso aroma, sabor e coloração avermelhada dos frutos, atributos de interesse atrativo e nutricional para o consumidor. Pigmentos carotenóides, além de serem precursores de vitamina A, atuam como antioxidantes, prevenindo a formação de tumores cancerígenos e reduzindo doenças cardiovasculares (Cândido e Campos, 1995; Slobodianik, 1995). Lipídeos têm sido associados com a cor e com o desenvolvimento do sabor dos frutos de manga durante o amadurecimento (Gomez-Lim, 1997). Cabe ressaltar que outras substâncias, como ésteres e compostos carbonila, estão também associadas ao aroma dos frutos (Subramanyam et al., 1975; Gomez-Lim, 1997). O índice de sólidos solúveis/acidez, correspondente aos conteúdos de açúcares e de acidez dos frutos, é um parâmetro apropriado para medir a percepção de sabor pelo consumidor.

A cultivar Espada Vermelha obteve os menores teores de açúcares redutores (2,61\%), pectina (0,85\%) e ácido ascórbico (31,3 mg/ $100 \mathrm{~g})$, porém os segundos menores valores de acidez total $(0,27 \%)$, de FAT (1,80\%), sólidos solúveis $\left(17,0{ }^{\circ}\right.$ Brix), sólidos totais $(17,08 \%)$, carboidratos totais $(15,16 \%$ ) e calorias de $68,2 \mathrm{kcal} / 100 \mathrm{~g}$ (Figuras 2a e 2b). Já as cultivares Votupa, Palmer e Van Dyke revelaram-se com algumas características opostas à 'Espada Vermelha'; maiores valores de acidez total (respectivamente, 0,48; 0,35; 0,44\%), de ácido ascórbico (46,6; 56,7; $38,3 \mathrm{mg} / 100 \mathrm{~g})$, e de forma geral, da fração de carboidratos totais (19,11; 18,78; 20,35\%), compreendendo as substâncias que a compõem bem como aquelas determinações químicas que estão correlacionadas com a fração, tais como os açúcares redutores (4,73; 4,08; 5,56\%), sólidos totais (20,67; 20,37; 21,78\%), sólidos solúveis (17,6; 17,9; 20,2 ${ }^{\circ}$ Brix) e, conseqüentemente, do valor calórico (80,9; 80,2; 84,0 kcal/100g). Entre as cultivares, Votupa e Palmer tiveram valores intermediários de carotenóides totais $(4,4 ; 4,0 \mathrm{mg} / 100 \mathrm{~g})$, de pectina $(0,88 ; 0,93 \%)$ e de lipídeos $(0,39 ; 0,49 \%)$, enquanto a 'Van Dyke' obteve os menores conteúdos de carotenóides totais (2,1 mg/100g), de lipídeos (0,18\%) e de $\mathrm{pH}(3,81)$, o que proporcionou o seu deslocamento, graficamente, para a direita, na Figura 2a.

Mukherjee (1997) cita que a acidez dos frutos está relacionada com a cultivar. Neste caso, podem-se agrupar as cultivares estudadas em dois grupos distintos: Espada Vermelha, Tommy Atkins e Haden 2H, posicionadas à esquerda da Figura 2a, como cultivares de baixa acidez (respectivamente, 0,27; 0,20; 0,29\%) e Palmer, Votupa e Van Dyke, à direita, com teores de acidez mais elevados $(0,35 ; 0,48 ; 0,44 \%)$.

A 'Haden 2H' e a cultivar Tommy Atkins, por serem genótipos aparentados (a 'Tommy Atkins' é filha da 'Haden'), evidenciaram características bem semelhantes (Figuras 2a e 2b), tais como, pH elevado (4,18; 4,37); baixos teores de sólidos totais $(17,40 ; 16,13 \%)$, de sólidos solúveis totais $\left(17,3 ; 16,6^{\circ}\right.$ Brix), acidez titulável $(0,29 ; 0,20)$, de lipídeos (0,29; 0,27\%), ácido ascórbico (36,6; 31,7 mg/100g), resíduo mineral fixo $(0,35 ; 0,33 \%)$, de carboidratos totais $(16,28 ; 14,99 \%)$ e de calorias $(68,3$; 
TABELA 6 - Composição mineral das cultivares de manga. ITAL, Campinas-SP, 1999-2000.

\begin{tabular}{|c|c|c|c|c|c|c|}
\hline \multirow[b]{2}{*}{ Determinações $^{1}$} & \multicolumn{6}{|c|}{ CULTIVAR } \\
\hline & Espada Vermelha & Haden 2H & Votupa & Palmer & Tommy Atkins & Van Dyke \\
\hline Cálcio (mg/100g) & $8,49 \pm 0,32$ & $10,83 \pm 2,53$ & $6,77^{ \pm} 0,20$ & $10,06^{ \pm} 0,20$ & $10,20 \pm 0,74$ & $8,56^{ \pm} 0,40$ \\
\hline Cobre (mg/100g) & $0,147 \pm 0,020$ & $0,104^{ \pm} 0,050$ & $0,116^{ \pm} 0,005$ & $0,069{ }^{ \pm} 0,017$ & $0,101{ }^{ \pm} 0,020$ & $0,102 \pm 0,042$ \\
\hline Ferro $(\mathrm{mg} / 100 \mathrm{~g})$ & $0,242 \pm 0,005$ & $0,189 \pm 0,030$ & $0,153{ }^{ \pm} 0,030$ & $0,117 \pm 0,017$ & $0,132 \pm 0,020$ & $0,174 \pm 0,017$ \\
\hline Fósforo $(\mathrm{mg} / 100 \mathrm{~g})$ & $14,5 \pm 0,5$ & $9,1^{ \pm} 1,7$ & $10,4 \pm 0,7$ & $8,9^{ \pm} 0,2$ & $9,5{ }^{ \pm} 0,2$ & $11,4 \pm 0,7$ \\
\hline Magnésio (mg/100g) & $14,4^{ \pm} 0,7$ & $9,5^{ \pm} 2,2$ & $8,9^{ \pm} 0,2$ & $8,3^{ \pm} 0,2$ & $8,2 \pm 0,5$ & $10,1^{ \pm} 0,0$ \\
\hline Manganês (mg/100g) & $0,471{ }^{ \pm} 0,014$ & $0,463{ }^{ \pm} 0,130$ & $0,175^{ \pm} 0,060$ & $0,406^{ \pm} 0,002$ & $0,346 \pm 0,025$ & $0,280 \pm 0,007$ \\
\hline Potássio (mg/100g) & $178 \pm 5$ & $126 \pm 22$ & $146 \pm 27$ & $171 \pm 2$ & $109 \pm 10$ & $165 \pm 17$ \\
\hline Zinco $(\mathrm{mg} / 100 \mathrm{~g})$ & $0,097 \pm 0,005$ & $0,064 \pm 0,017$ & $0,063 \pm 0,005$ & $0,044 \pm 0,005$ & $0,055 \pm 0,010$ & $0,063 \pm 0,002$ \\
\hline
\end{tabular}

${ }^{1}$ Valores médios de três repetições analíticas com intervalo de confiança da média, ao nível de 5\%.

63,6 kcal/100g). A cultivar Tommy Atkins destacou-se da 'Haden’ pela relação SST/acidez; a 'Tommy Atkins', apesar de ter o menor teor de sólidos solúveis totais, obteve a menor acidez, diferenciando-se pelo elevado índice obtido $(81,8)$ em relação à ‘Haden’ $(59,1)$ como também para as demais cultivares. A cultivar Votupa, embora tenha como descendência maternal a cultivar Tommy Atkins, não demonstrou ter herdado as suas características genéticas referentes à qualidade dos frutos, visto estar bem discriminada graficamente da sua progenitora (Figura 2a).

Botrel (1994) relata que tanto a acidez dos frutos como o teor de sólidos solúveis totais podem influenciar na aceitação das cultivares. Bleinroth et al. (1985), ao avaliarem 22 cultivares de mangas cultivadas no município de Tietê-SP, a maioria cultivares indianas melhoradas, vindas da Flórida, encontraram um teor médio de sólidos solúveis de 15,85 Brix, dentro de um intervalo de 12,1 a 19,0 ${ }^{\circ} \mathrm{Brix}$. Todas as cultivares selecionadas pelo IAC, como as comerciais, relativas a este experimento, apresentaram índices bons de sólidos solúveis, acima desta média (16,6 a $20,2^{\circ}$ Brix).

A parede celular dos frutos é composta de polissacarídeos, como a celulose, pectinas, hemicelulose e de compostos fenólicos (Brett e Waldron, 1990). A degradação da parede celular durante o amadurecimento relaciona-se com a textura e firmeza, que indicam o grau de maturação como também determina a vida de prateleira do fruto (Tucker, 1993). Manga é uma excelente fonte de fibra alimentar; ao se determinar esta fração em um alimento, estão sendo quantificados todos os polissacarídeos presentes na parede celular que não são digeridos ou absorvidos pelas enzimas humanas no trato gastrointestinal. Bleinroth et al. (1985) e Botrel (1994) consideram que o alto teor de fibras na polpa da manga é um fator negativo na qualidade da fruta. Do ponto de vista do processamento de subprodutos de manga, na forma de sobremesas, sorvetes e outros, este fator é verdadeiro. Subramanyam et al. (1975) classificam mangas em duas categorias: as de polpa carnosa e as suculentas. Segundo os autores, as carnosas, de polpa firme, livres de fibras e com boa coloração, sabor e aroma, são preferidas para serem processadas e embaladas em fatias; as do tipo suculentas são fibrosas, ricas em cor e sabor, são usadas para a produção de néctar ou bebidas à base de frutas. Entretanto, quanto ao aspecto nutricional, a questão "presença de fibras na fruta" deve ser revista. Estudos sobre fibras da dieta têm mostrado bons efeitos fisiológicos, dentre muitos, diminuem o colesterol plasmático, regularizam o funcionamento intestinal, previnem e tratam doença diverticular do cólon, previnem o câncer de cólon e são consideradas importantes nutrientes para o controle da absorção da glicose, especialmente para pessoas diabéticas, visto que dietas ricas em fibra alimentar promovem menor aumento glicêmico após as refeições (Cavalcanti, 1989). Por meio de análise concomitante dos gráficos da Figura 2 e Tabela 5, verificou-se que as cultivares Van Dyke, Haden e Tommy Atkins, consideradas como de boa qualidade comercial, foram as que apresentaram os maiores teores de FAT e de pectina.

Os sais minerais estão relacionados à saúde humana, uma vez que sua deficiência ou excesso pode induzir mudanças fisiológicas nos indivíduos. Alguns elementos, quando presentes em altas concentrações nos alimentos, ou mesmo em concentrações muito baixas, podem afetar o metabolismo e são conhecidos como elementos essenciais, sendo ao todo 26 elementos essenciais para o homem. Nas cultivares de manga, foram determinados os níveis de 8 dos 26 elementos essenciais, demonstrados na Tabela 6.

Analisando as Figuras 3a e 3b, correspondentes ao tratamento estatístico dos níveis dos elementos minerais determinados, novamente a 'Espada Vermelha' destacou-se das demais cultivares (lado direito da Figura 3a) por ter as maiores concentrações da maioria dos minerais determinados (Cu, Fe, P, Mg, K e Zn - Figura 3b). 'Tommy Atkins' e 'Palmer' exibiram comportamento inverso à 'Espada Vermelha', posicionando-se graficamente à esquerda da figura, por terem os menores valores para a maioria destes elementos minerais (Tabela 6). A 'Espada Vermelha', juntamente com 'Van Dyke' e 'Votupa', obteve os menores teores de Ca (8,49; 8,56; 6,77 mg/100g) enquanto 'Haden 2H', 'Palmer’ e

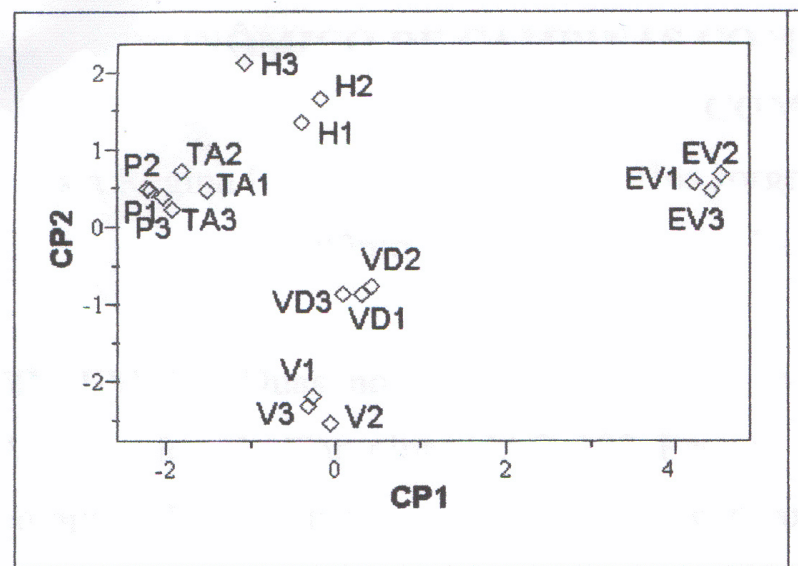

a) gráfico de escores

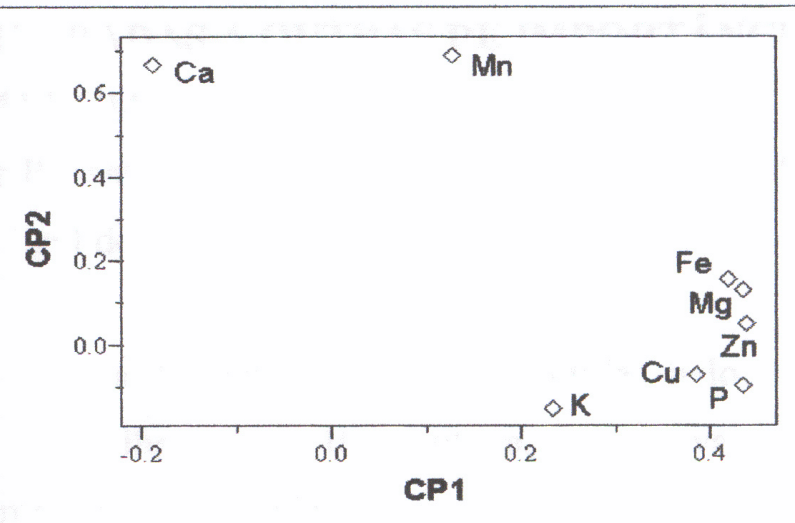

b) gráfico de pesos

FIGURA 3 - Gráficos de componentes principais (CP1 x CP2) obtidos para as concentrações dos elementos minerais dos frutos de manga - préprocessamento utilizado: auto-escalamento. a) gráfico de escores: P1 a P3 - ‘Palmer’; TA1 a TA3 - 'Tommy Atkins'; H1 a H3 - ‘Haden 2H’; VD1 a VD3 - 'Van Dyke’; V1 a V3 - 'Votupa'; EV1 a EV3 - ‘Espada Vermelha’. b) gráfico de pesos: Ca - cálcio; Mn - manganês; K - potássio; $\mathrm{Fe}$ - ferro; Mg - magnésio; $\mathrm{Zn}$ - zinco; $\mathrm{Cu}$ - cobre; $\mathrm{P}$ - fósforo. 
'Tommy Atkins' apresentaram os maiores valores do mesmo elemento (respectivamente, 10,83; 10,06; e 10,20 mg/100g). 'Votupa' obteve o menor teor de Mn (0,175 mg/100g), seguida pela 'Van Dyke' (0,280 mg/100g), ao passo que 'Espada Vermelha' e 'Haden' apresentaram concentrações mais elevadas para esse mineral $(0,471 ; 0,463 \mathrm{mg} / 100 \mathrm{~g})$.

Os níveis dos minerais encontrados em todas as cultivares estudadas são baixos para serem considerados como fonte de minerais, porém eles podem contribuir para a dieta alimentar, juntamente com outros alimentos, principalmente em termos dos micronutrientes ferro e manganês.

A cutlivar Votupa apresentou o mesmo ciclo da 'Palmer' sendo, portanto, sua competidora direta na disputa pelo mercado. A única vantagem expressiva que apresentou sobre a 'Palmer' foi sua resistência à seca-da-mangueira para qual foi selecionada. A 'Palmer' teve maior produtividade e é mais atrativa. A 'Votupa' deverá ser recomendada como cultivar semitardia para substituir pomares que foram dizimados pela seca-da-mangueira.

A cultivar Espada Vermelha mostrou-se mais precoce que a 'Tommy Atkins', não tendo, portanto, concorrência com a principal cultivar do mercado. Apresentou boa resistência à mosca-das-frutas, características nutricionais diferenciadas, aroma e sabor agradáveis e visual muito atraente. Mostrou-se suscetível à antracnose com menor capacidade de conservação pós-colheita, o que limita o seu potencial para exportação. Adapta-se para plantio em regiões quentes com menor umidade no ar, que potencializa sua precocidade e reduz a incidência da antracnose, como a Noroeste do Estado de São Paulo, para a produção de frutos precoces para o mercado interno.

\section{CONCLUSÕES}

1. Classificou-se, nas condições edafoclimáticas de Votuporanga-SP, usando como critério a época de produção/maturação dos frutos, as cultivares Espada Vermelha, Haden 2H e Van Dyke como precoces, Tommy Atkins como de meia-estação e Votupa e Palmer como tardias.

2. Em relação à produção das plantas nas safras de 20012002 e 2002-2003, a cultivar Espada Vermelha apresentou a menor produtividade, enquanto a 'Palmer' foi a mais produtiva. 'Votupa', 'Van Dyke' e 'Tommy Atkins' obtiveram produções intermediárias e comparáveis entre si. 'Haden $2 \mathrm{H}$ ' foi muito produtiva, mas mostrou alternância de produção e foi suscetível ao intenso calor da região.

3. Nenhuma cultivar foi resistente a todas as principais doenças. Todas as cultivares foram suscetíveis à malformação da inflorescência. A 'Haden 2H' foi a cultivar com maior suscetibilidade às doenças.

4. A cultivar Espada Vermelha foi mais resistente à moscadas-frutas do que as demais cultivares avaliadas.

5. As cultivares Votupa, Palmer, Tommy Atkins e Van Dyke atingiram altos rendimentos de polpa (> 80\%).

6. 'Palmer'e 'Van Dyke' apresentaram similares características químicas, demonstrando, estas cultivares, em conjunto com a Votupa, serem mais calóricas e mais ácidas. 'Espada Vermelha', 'Tommy Atkins' e 'Haden 2H', apesar de poderem ser classificadas como cultivares de baixo valor calórico, apresentaram os melhores índices de sólidos solúveis totais/acidez devido à baixa acidez de seus frutos.

7. A cultivar Espada Vermelha obteve atributos diferenciados para todas as características avaliadas, demonstrando ser rica em minerais, carotenóides totais, lipídeos e proteína bruta, alta relação sólidos solúveis totais/acidez, possuindo bom sabor e intenso aroma agradável. Com visual muito atrativo, precoce e suscetível à antracnose, é recomendada para cultivo em regiões quentes com baixa umidade no ar, para produção precoce para o mercado interno.

8. A cultivar Votupa é recomendada como cultivar semitardia para substituir pomares dizimados pela seca-da-mangueira.

\section{REFERÊNCIAS BIBLIOGRÁFICAS}

BEEBE, K.R.; PELL, R.J.; SEASHOLTZ, M.B. Chemometrics: a practical guide. New York: John Wiley \& Sons Inc., 1998. 348p.

BLEINROTH, E.W.; FIGUEIREDO, I.B. de; VEIGA, A. de A.; SOARES, N.B.; MEDINA, J.C.; SABINO, J.C. Avaliação de novas cultivares de manga para industrialização. I. Análise das características físicogeométricas e químicas da matéria-prima. Boletim do Instituto de Tecnologia de Alimentos, Campinas, v.22, n. 2, p. 217-246, 1985.

BOTREL, N. Manga: Variedades, Qualidade e Tecnologia Pós-Colheita. Informe Agropecuário, Belo Horizonte, v.17, n. 179, p.55-60, 1994.

BRASIL. Ministério da Integração Nacional. Manga. Brasília, 1999, 4p. (FrutiSéries, 2 - Minas Gerais).

BRETT, C.; WALDRON, K. Physiology and Biochemistry of Plant Cell Walls. London: Unwin Hyman, 1990. p. 169-175.

CÂNDIDO, L.M.B.; CAMPOS, A. M. Alimentos Funcionais - Uma Revisão. Boletim da Sociedade Brasileira de Ciência e Tecnologia deAlimentos, Campinas, v. 29, n. 2, p.193-203, 1995.

CARVALHO, C.R.L.; MANTOVANI, D.M.B.; CARVALHO, P.R.N.; MORAES, R.M.de. Análises químicas de alimentos. Campinas: Instituto de Tecnologia de Alimentos, 1990. 121p. (Manual Técnico)

CAVALCANTI, M.L.F. Fibras Alimentares. Revista de Nutrição da Puccamp, Campinas, v.2, n. 1, p. 88-97, 1989.

COUTO, F.A.A.; SIQUEIRA, D.L.; RABELO, J.E.S. Situação e perspectiva da mangicultura no Estado de Minas Gerais. In: SÃO JOSÉ, A. R.; SOUZA, I.V.B.; MARTINS FILHO, J.; MORAES, O.M.(Ed.) Manga: tecnologia de produção e mercado. Vitória da Conquista: DFZ/UESB, 1996. p. 322-328.

CUNNIF, P. (Ed.). Official Methods of Analysis. 16th ed. Gaithersburg: Association of Official Analytical Chemists International, 1998. 2v.

DONADIO, L.C.; SOARES, N.B.; MORAES, L. G.; XAVIER, N.J.D.; SCALOPI, E.J.; PIZA JUNIOR, C.T. Características de algumas variedades de mangueira cultivadas no Estado de São Paulo. São Paulo: CATI, 1982. 16p. (CATI. Boletim Técnico, 171).

DONADIO, L.C. Variedades de Mangueira. In: SÃO JOSÉ, A. R.; SOUZA, I.V.B.; MARTINS FILHO, J.; MORAES, O.M. (Ed.) Manga: tecnologia de produção e mercado. Vitória da Conquista: DFZ/UESB, 1996. p. 32-56.

GENÚ, P.J. de C.; PINTO, A.C. de Q. (Ed.) A cultura da mangueira. Brasília: EMBRAPA, 2002, 452p.

GOMEZ-LIM, M.A. Postharvest Physiology. In: LITZ, R.E. (Ed.) The Mango: botany, production and uses. Wallingford: CAB INTERNATIONAL, 1997. p. 425-445.

IMO INDUSTRIES. Baird Analytical Instruments Division. ICP 2000 Spectrometer User's Guide. Bedford, Massachusetts, USA, 1990. 102p.

MORGANO, M.A.; QUEIROZ, S.C. do N. de; FERREIRA, M.M.C. Aplicação da análise exploratória na diferenciação de vegetais. Brazilian Journal of Food Technology, Campinas, v. 2, n. 1/2, p. 7379, 1999.

MUKHERJEE, S.K. Introduction: Botany and Importance. In: LITZ, R.E. (Ed.) The Mango: botany, production and uses. Wallingford: CAB INTERNATIONAL, 1997. p. 1-19.

PAINTER, R.H. Insect resistance in crop plants. New York: The MacMillan Company, 1951.520p.

PIZA JR., C. T.; RIBEIRO, I.J.A. Principais Doenças da Mangueira. In: SÃO JOSÉ, A. R.; SOUZA, I.V.B.; MARTINS FILHO, J.; MORAES, O.M. (Ed.) Manga: tecnologia de produção e mercado. Vitória da Conquista: DFZ/UESB, 1996. p. 167-201.

PINTO, A.C. de Q.; COSTA, J.G. da; SANTOS, C.A.F. Principais variedades. In: GENÚ, P.J. de C.; PINTO, A.C. de Q. (Ed.) A cultura da mangueira. Brasília: EMBRAPA, 2002, p. 95-116.

ROSSETTO, C.J.; RIBEIRO, I.J.A.; GALLO, P.B.; CARVALHO, R.P.de L. Pragas da mangueira e seu controle. In: DONADIO, L.C.; FERREIRA, 
F.R. (Ed.) SIMPÓSIO SOBRE MANGINCULTURA, 2., 1989, Jaboticabal. Anais... Jaboticabal: FCAV-UNESP, 1989. p. 133-148.

ROSSETTO, C.J.; RIBEIRO, I.J.A.; IGUE, T; GALLO, P.B. Seca-damangueira: XV. Resistência varietal a dois isolados de Ceratocystis fimbriata. Bragantia, Campinas, v. 55, n.1, p. 117-121, 1996.

ROSSETTO, C.J.; BORTOLETTO, N.; CASTRO, J.V. de; CARVALHO, C.R.L.; IGUE, T. Response of mango varieties to pachlobutrazol. In: INTERNACIONAL MANGO SYMPOSIUM, 7., Recife, 2002. Program and Abstracts... Fortaleza: Embrapa, 2002. p.176.

SÃO JOSÉ, A. R. Considerações Gerais sobre a Mangicultura. In: SÃO JOSÉ, A. R.; SOUZA, I.V.B.; MARTINS FILHO, J.; MORAES, O.M. (Ed.) Manga: tecnologia de produção e mercado. Vitória da Conquista: DFZ/UESB, 1996. p. 1-6.

SHARAF, M.A.; ILLMAN, D.L.; KOWALSKI, B.R. Chemometrics. New York: John Wiley \& Sons Inc., 1986. 332p.
SLOBODIANIK, N. H. Nutrientes e Inmunidad: Buenas y Malas Noticias. Boletim da Sociedade Brasileira de Ciência e Tecnologia de Alimentos, Campinas, v. 29, n. 2, p.164-169, 1995.

SOUZA, J. da S.; ALMEIDA, C.O. de; ARAÚJO, J.L.P.; CARDOSO, C.E.L. Aspectos socioeconômicos. In: GENÚ, P.J.de C.; PINTO, A.C. de Q. (Ed.) A cultura da mangueira. Brasília: Embrapa, 2002. p. 2029.

SUBRAMANYAM, H.; KRISHNAMURTHY, S.; PARPIA, H.A.B. Physiology and Biochemistry of Mango Fruit. In: CHICHESTER, C.O.; MRAK, E.M.; STEWART, G.F. (Ed.) Advances in food research. New York: Academic Press, 1975. v. 21, p. 223-305.

TUCKER, G.A. Introdution. In: SEYMOUR, G.; TAYLOR, J.; TUCKER, G. (Ed.) Biochemistry of fruit ripening. London: Academic Press, 1993. p.1-51. 